\section{BEHAVIOURAL SAMPLING TECHNIQUES AND ACTIVITY PATTERN OF Indian Pangolin Manis CRAssicaudata (Mammalia: Manidae) IN CAPTIVITY}

\section{Rajesh Kumar Mohapatra ${ }^{1} \&$ Sudarsan Panda ${ }^{2}$}

${ }^{1}$ Pangolin Conservation and Breeding Center, Nandankanan Zoological Park, Baranga, Khurda, Odisha 754005, India ${ }^{2}$ Nandankanan Zoological Park, Mayur Bhawan, Saheed Nagar, Bhubaneswar, Odisha 751007, India

${ }^{1}$ rajesh.wildlife@gmail.com (corresponding author), ${ }^{2}$ sudarsanpanda61@gmail.com

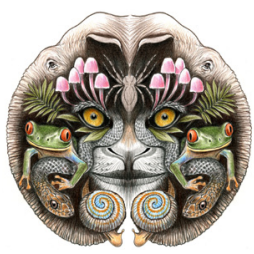

ISSN

Online 0974-7907 Print 0974-7893

\begin{abstract}
The study presents data on six Indian Pangolins Manis crassicaudata observed in captivity at the Pangolin Conservation Breeding Centre, Nandankanan, Odisha, India over 1377 hours of video recordings for each pangolin between $1500 \mathrm{hr}$ and $0800 \mathrm{hr}$ on 81 consecutive observational days. Video recordings were made through digital systems assisted by infrared enabled CCTV cameras. The data highlights patterns relate to 12 different behaviour and enclosure utilization. Different interval periods for sampling of instantaneous behaviour from video recordings have been evaluated to develop optimal study methods for the future. The activity budgets of pangolins displayed natural patterns of nocturnal activity with a peak between 20:00-21:00 hr. When out of their burrow, they spent about 59\% of the time walking in the enclosure, and $14 \%$ of the time feeding. The repeatability of the behaviours has a significant negative correlation with the mean time spent in that behaviour. Focal behavioural samples significantly correlated with instantaneous samples up to 15 minutes interval. The correlation values gradually decreased with the increase in sampling interval. The results indicate that results obtained from focal sampling and instantaneous sampling with relatively shorter intervals ( $\leq 5$ minutes) are about equally reliable. The study suggests use of focal sampling, instead of instantaneous sampling to record behaviour relating to social interactions.
\end{abstract}

Keywords: Activity budget, behavioural sampling, focal sampling, Indian Pangolin, instantaneous sampling, Nandankanan.

DOI: http://dx.doi.org/10.11609/JoTT.o3423.5247-55 | ZooBank: urn:Isid:zoobank.org:pub:D5A984AF-8842-4C72-9C44-F315D8076C9E

Editor: L.A.K. Singh, Bhubaneswar, Odisha, India.

Date of publication: 26 December 2013 (online \& print)

Manuscript details: Ms \# 03423 | Received 03 December 2012 | Final received 05 July 2013 | Finally accepted 11 November 2013

Citation: Mohapatra, R.K. \& S. Panda (2013). Behavioural sampling techniques and activity pattern of Indian Pangolin Manis crassicaudata (Mammalia: Manidae) in captivity. Journal of Threatened Taxa 5(17): 5247-5255; http://dx.doi.org/10.11609/JoTT.03423.5247-55

Copyright: @ Mohapatra \& Panda 2013. Creative Commons Attribution 3.0 Unported License. JoTT allows unrestricted use of this article in any medium, reproduction and distribution by providing adequate credit to the authors and the source of publication.

Funding: This study is a part of the research project funded by Central Zoo Authority, New Delhi.

Competing Interest: Authors declare no competing interests.

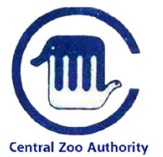

Author Details: R.K. MOHAPATRA is working as Junior Research Fellow; has registered for his PhD in Utkal University, Odisha with an objective to understand behavioural patterns, space utilization, reproductive biology, haematology, effect of environmental enrichment and identification of ecto- and endo-parasites of captive Indian pangolins which will be ultimately helpful in captive management and breeding of the species. DR. S. PANDA is currently working as Director, Nandankanan Biological Park, Odisha. He is the project investigator of the research project. He has co-authored 7 books and 30 research papers in the field of wildlife and biodiversity. His research interest includes wildlife conservation, in-situ and ex-situ management of wildlife and biodiversity studies.

Author Contribution: Both authors conceived the study, participated in its design and coordination. RKM contributed in behavioural data collection, data analysis, review of literature and in drafting the manuscript. Both authors contributed to revision of the manuscript and approved the final manuscript.

Acknowledgements: The authors wish to extend their sincere thanks to the Central Zoo Authority, New Delhi for their financial support in undertaking the research work in Pangolin Conservation Breeding Center at Nandankanan Zoological Park, Odisha, India. 


\section{INTRODUCTION}

Pangolins are toothless small mammals with overlapping horny scales on their body, protrusible long tongue and prehensile tail, rolling up into a ball when threatened. They belong to the family Manidae of order Pholidota. Indian Pangolin Manis crassicaudata distributed throughout peninsular India, Sri Lanka, Bangladesh and Pakistan (Heath 1995; Molur 2008). The Indian Pangolin is included under Appendix II of CITES, as 'Near Threatened' under the IUCN Red List (Molur 2008), and as a Schedule I animal of the Indian Wildlife (Protection) Act, 1972. For better management, welfare and breeding in captivity there is need for a better understanding of their behaviour.

Behaviour is the exhibition of a phenotypic trait within the environmental context for which primary selective forces have shaped it, the outcome of which is inclusive fitness (Eisenberg 1981). Behavioural monitoring is a demonstrated technique that can improve the welfare of animals in zoos (Kleiman 1992), and meet conservation goals (Watters et al. 2009). Behavioural sampling method is crucial to understanding and interpreting behaviour of an animal, because sampling bias does not change the behaviour of the animal but can affect the efficiency and reliability of data collection (Fragaszy et al. 1992)

There are different methods of behavioural sampling (Altmann 1974; Martin \& Bateson 1993; Lehner 1996). 'Focal sampling' is simple and easy to use in a wide variety of environments (Tyler 1979; Losito et al. 1989). 'Focal sampling' requires the use of a stopwatch for precise recording of the transition times between activity states. As described by Altmann (1974), 'instantaneous sampling' records the state at fixed time points. Choosing an appropriate interval between sample points is essential, particularly for 'bout lengths' for meaningful and unambiguous 'instantaneous sampling' (Engel 1996).
The present study aimed at finding out the timebudget for various above-ground activities of captive Indian Pangolins. The study also determined the optimal sampling interval for behavioural data collection with instantaneous sampling technique.

\section{MATERIALS AND METHODS}

\section{Animals and housing conditions}

The study was conducted between February 2012 and April 2012 on six (three males and three females) Manis crassicaudata at the "Pangolin Conservation Breeding Centre" of Nandankanan Zoological Park, Odisha, India (Table 1). Each pangolin was individually housed in an enclosure $4.8 \times 4.2 \times 3.0 \mathrm{~m}$ in dimension, where $0.5 \mathrm{~m}$ deep red laterite soil was provided as substrate over a reinforced concrete base to prevent digging and escape of the animal. On all four sides above the concrete base there was a reinforced concrete wall up to a height of $1.0 \mathrm{~m}$, above which chain-link mesh was provided on all four sides upto the concrete roof. An earthen mound, $2 \times 2 \mathrm{~m}$, and some hollow wooden logs and wooden poles provided enrichment material in each enclosure. The pangolins were microchipped with a passive integrated transponder (PIT) for their individual identity. The microchip number and a short reference name for each pangolin are given in Table 1. The daily husbandry routine consisted of enclosure cleaning, water maintenance, feeding and health monitoring. Health monitoring comprised of (i) observation through video recordings to detect inactivity or change in behaviour, (ii) intermittent direct observation for any sickness, and (iii) faecal sample examination to detect the presence of gastrointestinal parasites. Every month physical examinations were carried out with each pangolin for measuring the length and weight of the body, for detection of any injury or external parasites and for secretion from their natural orifices like nose,

Table 1. Information about gender, body weight, length and date of birth (DOB) or date of acquisition (AD) of pangolins studied at Nandankanan. Body length and weight were measured on 18 March 2012. DOB data are shown with an asterisk.

\begin{tabular}{|c|c|c|c|c|c|c|}
\hline Pangolin ID & Microchip No. & Gender & AD/DOB* & Mass (g) & Total length (cm) & Tail length (cm) \\
\hline PA6F & 0006A2AA6F & Female & 16.07 .2000 & 9810 & 78 & 39 \\
\hline P395 & 0006A2A395 & Female & 02.01 .2008 & 10590 & 100 & 51 \\
\hline P160 & 98102056160 & Female & 17.09 .2008 & 9000 & 87 & 46 \\
\hline P3F9 & 0006A283F9 & Male & 09.11 .2007 & 10805 & 93 & 47 \\
\hline P473 & 98102055473 & Male & $17.07 .2009 *$ & 9880 & 92 & 48 \\
\hline P5FE & 00071515FE & Male & $28.08 .2009 *$ & 12050 & 102 & 51 \\
\hline
\end{tabular}


mouth and genitalia. During the study period all the pangolins were healthy and didn't show any adverse health parameters. The average temperature during the study period was $28.4^{\circ} \mathrm{C}$, whereas the maximum and minimum values recorded inside the enclosure were $22.1^{\circ} \mathrm{C}$ and $32.3^{\circ} \mathrm{C}$, respectively.

\section{Behavioural observation}

The following terms are used to describe present behavioural study: (i) 'Ethogram'- a complete inventory of the behaviour patterns of species (Tinbergen 1951); (ii) 'Focal Sampling' - continuous behavioural observation that records each sample period for each focal individual (Altmann 1974); (iii) 'Instantaneous behavioural sampling'- the documentation of individual's current activity at preselected moments in time (Altmann 1974); (iv) 'Activity pattern'- the time spent in different aboveground behaviour when pangolins could be observed through CCTV (close circuit television) cameras.

Data for this study was obtained from six numbers of pangolins and comprised 1377 hours of video recordings for each pangolin between 1500 and 0800 hr on 81 consecutive observational nights. Since the Indian pangolins are nocturnal, secretive, solitary and intermittently active, behavioural observation was

Table 2. Behavioral activities of Manis crassicaudata used for constructing ethogram in the study.

\begin{tabular}{|l|l|}
\hline Behaviour & Definition \\
\hline Bathing (BA) & Individual lying submerged or moving inside water pool. \\
\hline $\begin{array}{l}\text { Bipedal Stand } \\
\text { (BS) }\end{array}$ & $\begin{array}{l}\text { Standing on its legs with head elevated to survey the } \\
\text { surroundings. }\end{array}$ \\
\hline Climbing (CL) & $\begin{array}{l}\text { Climbing movement on wire mesh or on dry tree } \\
\text { branches. }\end{array}$ \\
\hline Coiling (CO) & Rolling itself in to a sphere. \\
\hline Digging (DI) & $\begin{array}{l}\text { Scooping of soil by forelimbs and throwing the dugout } \\
\text { soil using hind limbs. }\end{array}$ \\
\hline Drinking (DR) & $\begin{array}{l}\text { Head lowered below level of back and consuming water } \\
\text { by lapping movement of tongue. }\end{array}$ \\
\hline Exploration \\
(EX) & $\begin{array}{l}\text { Short head movements directed towards pangolin's } \\
\text { proximate environment usually followed by sniffing or } \\
\text { touching the substrate by snout or forelimb. }\end{array}$ \\
\hline Feeding (FI) & $\begin{array}{l}\text { Head lowered below the level of back and consuming } \\
\text { ants and termites using frequent in and out movement } \\
\text { of tongue. }\end{array}$ \\
\hline Pacing (PC) & $\begin{array}{l}\text { Repetitive quadrupedal waking movements in same } \\
\text { path. }\end{array}$ \\
\hline Secretive (SC) & $\begin{array}{l}\text { Looking out from the mound holes while the entire body } \\
\text { is inside the burrow, head visible. }\end{array}$ \\
\hline Interaction (SI) & $\begin{array}{l}\text { Interaction between the individuals of neighbouring } \\
\text { enclosures along chain-linked mesh. (Mother-young } \\
\text { and male-female interactions have not been included in } \\
\text { this study.) }\end{array}$ \\
\hline $\begin{array}{l}\text { Forward progression in a typical quadrupedal movement } \\
\text { and tail usually held up the ground. }\end{array}$ \\
\hline $\begin{array}{l}\text { Urination, defecation or any other behaviour not } \\
\text { included in the ethogram. }\end{array}$ \\
\hline Other
\end{tabular}

made through digital video recording system assisted by infrared enabled CCTV cameras installed at each enclosure using focal animal sampling. Though the enclosures of each pangolin were regularly inspected during the remaining time, i.e., from 0800 to $1500 \mathrm{hr}$, of the observational day, no above-ground activity was observed and was not subjected to analysis. An ethogram of commonly observed behaviour of pangolins was prepared from the preliminary observations (Table 2 ). The observed behaviours with their respective time intervals were documented in Excel worksheets.

The 'focal samples' comprised of the durations of respective behavioural events extracted by continuous behavioural scan from recorded video files. The focal samples were used to create instantaneous sample data set. For example, behavioural scans at every $60^{\text {th }}$ second were used to create the instantaneous sample for a oneminute interval. Similar behavioural scans were carried out to prepare instantaneous samples at 2, 3, 4, 5, 10, 15,20 and 30 minute intervals. When behaviour was measured with instantaneous sampling at intervals, the sampled behavioural data stands for all the behavioural events that occurred during that particular interval. Therefore, 'instantaneous behavioural samples' at different intervals, extracted from the 'focal behavioural samples' were multiplied with the sampling interval to represent 'behavioural score'.

\section{Data analysis}

Estimates of sample size included mean, standard deviation and standard error calculated for focal behavioural samples as well as instantaneous behavioural samples. The mean 'bout duration' of any behaviour was calculated by extracting at least 50 samples from focal sampling data during initial observations. Similarly, the 'mean duration of repeatability' of any behaviour was calculated from more than 30 samples extracted from the focal sampling data. Spearman rank-order correlations $\left(r_{s}\right)$ were calculated to correlate mean bout duration, mean duration of repeatability and mean time spent in displaying the behaviour. To find out optimal sampling interval for Instantaneous behavioural sampling, the behavioural data from focal samples and instantaneous samples at different intervals were subjected to the following statistical tests. Pearson product correlations ( $r$ ) were used to correlate average time spent in different behaviour. Analysis of variance (Zar 1984) was used to test the null hypothesis that the expected means of all samples taken by different sampling methods are equal. Rejection of null hypothesis only implies that the group means were not the same. To find out the 
Table 3. Mean time spent ( \pm standard deviation) in different behaviours by individual Indian Pangolin. Numerals in each cell represent time recorded in minutes.

\begin{tabular}{|c|c|c|c|c|c|c|}
\hline Behaviour & PA6F & P395 & P160 & P3F9 & P473 & P5FE \\
\hline Bathing & $0.09 \pm 0.14$ & 0 & $0.07 \pm 0.13$ & $0.51 \pm 0.83$ & $0.21 \pm 0.31$ & $0.35 \pm 0.51$ \\
\hline Bipedal stand & $0.24 \pm 0.39$ & $0.31 \pm 0.36$ & $0.15 \pm 0.24$ & $2.35 \pm 1.93$ & $028 \pm 0.32$ & $1.92 \pm 1.80$ \\
\hline Climbing & $0.59 \pm 0.83$ & $0.02 \pm 0.05$ & $0.13 \pm 0.22$ & $1.67 \pm 1.93$ & $0.35 \pm 0.51$ & $2.48 \pm 2.31$ \\
\hline Coiling & $0.22 \pm 0.39$ & $0.30 \pm 0.49$ & $0.10 \pm 0.18$ & $0.15 \pm 0.27$ & $2.60 \pm 4.23$ & $0.02 \pm 0.04$ \\
\hline Digging & $0.78 \pm 1.07$ & $0.12 \pm 0.21$ & $2.02 \pm 2.51$ & $7.98 \pm 8.42$ & $0.18 \pm 0.31$ & $26.53 \pm 18.02$ \\
\hline Drinking & $0.19 \pm 0.31$ & $0.43 \pm 0.55$ & $0.19 \pm 0.33$ & $0.39 \pm 0.32$ & $0.57 \pm 0.70$ & $2.57 \pm 2.36$ \\
\hline Exploration & $2.20 \pm 1.63$ & $4.29 \pm 3.37$ & $2.80 \pm 2.81$ & $9.94 \pm 5.87$ & $5.37 \pm 4.84$ & $9.01 \pm 5.92$ \\
\hline Feeding & $9.24 \pm 4.31$ & $5.81 \pm 2.43$ & $17.41 \pm 7.57$ & $20.88 \pm 10.57$ & $9.81 \pm 3.38$ & $15.44 \pm 7.67$ \\
\hline Pacing & $0.04 \pm 0.08$ & 0 & $0.12 \pm 0.22$ & 0 & $6.76 \pm 11.46$ & $194.48 \pm 88.57$ \\
\hline Secretive & $0.04 \pm 0.08$ & $2.54 \pm 2.34$ & $0.01 \pm 0.02$ & $0.01 \pm 0.02$ & $0.04 \pm 0.08$ & $0.11 \pm 0.21$ \\
\hline Social interaction & $0.93 \pm 1.06$ & $0.90 \pm 1.05$ & $3.29 \pm 2.54$ & $6.54 \pm 3.22$ & $0.06 \pm 0.10$ & $0.89 \pm 0.74$ \\
\hline Walking & $51.30 \pm 43.80$ & $8.65 \pm 6.14$ & $81.94 \pm 67.12$ & $117.19 \pm 50.73$ & $90.95 \pm 82.91$ & $28.80 \pm 12.32$ \\
\hline Total average activity time & $65.87 \pm 48.22$ & $23.37 \pm 12.84$ & $108.23 \pm 76.34$ & $167.62 \pm 66.47$ & $117.19 \pm 93.00$ & $282.62 \pm 115.86$ \\
\hline
\end{tabular}

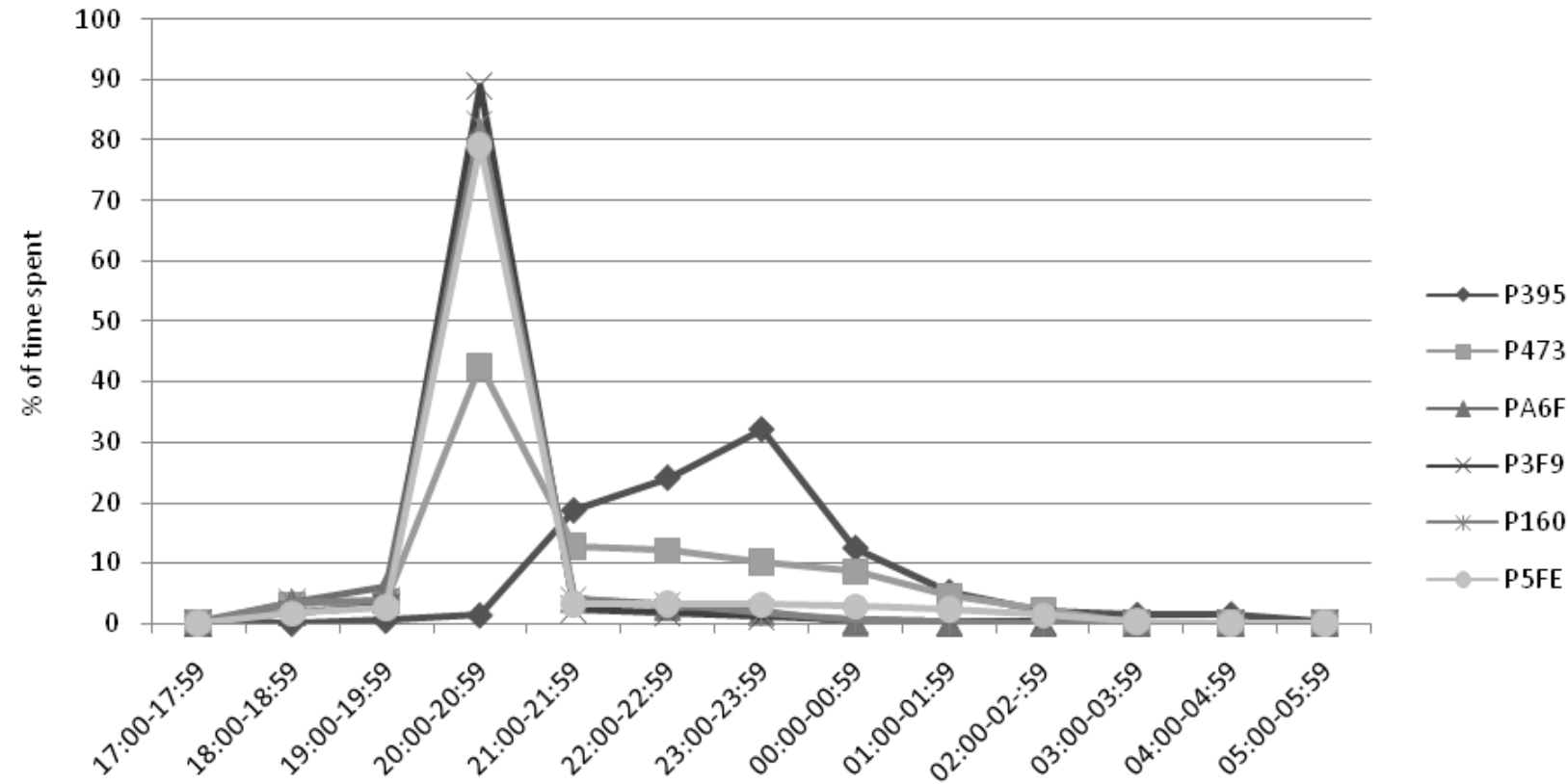

Activity time

Figure 1. Activity pattern of individual Indian Pangolins (Manis crassicaudata) in captivity. The symbols refer to individual pangolins. Data presented here is the temporal distribution of total average activity time given in Table 3.

way in which the group means were different, Fisher's Least Significant Difference (LSD) was conducted for pair-wise comparisons of sample means at same level of significance (Chainy 2004; Meier 2006).

The focal behavioural sampling data were used for generating patterns relating to the above-ground activities. The patterns included 'total activity time' and the 'duration of time spent' for any behaviour (Tables
$2 \& 3)$. The average activity pattern for each individual pangolin was calculated by converting the minute-based time duration of behaviour to percentage of time spent.

Behavioural diversity of individual pangolins was calculated by Shannon-Weiner index $(H)$ using PAST (Paleontological Statistics ver. 2.12). All behavioural states were utilised for the calculation of ShannonWeiner index (Magurran 1988). To quantify the 'space 
Table 4. Mean and standard error (SE) of different behaviours measured by different sampling techniques. Numerals in each cell represent time recorded in minutes. ${ }^{\prime * \prime}=\mathrm{SE}$ is the pooled standard error of the means.

\begin{tabular}{|c|c|c|c|c|c|c|c|c|c|c|c|c|c|}
\hline \multirow{2}{*}{ Behaviours } & \multirow{2}{*}{$\begin{array}{l}\text { Mean } \\
\text { bout } \\
\text { duration }\end{array}$} & \multirow{2}{*}{$\begin{array}{l}\text { Mean } \\
\text { repeatability } \\
\text { interval }\end{array}$} & \multirow{2}{*}{$\begin{array}{l}\text { Focal } \\
\text { sample } \\
\text { mean }\end{array}$} & \multicolumn{9}{|c|}{ Mean of instantaneous samples, minute intervals between scans } & \multirow{2}{*}{ SE* } \\
\hline & & & & 1 & 2 & 3 & 4 & 5 & 10 & 15 & 20 & 30 & \\
\hline Bathing & 1.5 & 1883.8 & 0.2 & 0.2 & 0.2 & 0.2 & 0.2 & 0.2 & 0.5 & 0.4 & 0.1 & 0.4 & 0.04 \\
\hline Bipedal Stand & 0.5 & 174.4 & 0.9 & 1 & 1 & 0.9 & 1.2 & 1 & 1.5 & 0.6 & 1 & 0.4 & 0.101 \\
\hline Climbing & 3.4 & 452.4 & 0.6 & 0.6 & 0.6 & 0.6 & 0.6 & 0.6 & 1.1 & 0.5 & 0.5 & 0.6 & 0.054 \\
\hline Coiling & 0.7 & 522.8 & 0.9 & 0.9 & 0.9 & 1 & 0.8 & 0.7 & 1.6 & 1.2 & 0.8 & 0.8 & 0.078 \\
\hline Digging & 6.2 & 33.4 & 6.3 & 6.3 & 6.3 & 6.2 & 6.4 & 6.2 & 11.3 & 6.4 & 5.8 & 5 & 0.539 \\
\hline Drinking & 0.7 & 1541.9 & 0.7 & 0.7 & 0.7 & 0.8 & 0.6 & 0.9 & 1.8 & 1 & 0.8 & 1.5 & 0.123 \\
\hline Exploration & 0.6 & 26.9 & 5.6 & 5.9 & 5.9 & 6.6 & 5.9 & 5.6 & 12.1 & 6.3 & 5.5 & 5.5 & 0.63 \\
\hline Feeding & 4.9 & 3.4 & 13.1 & 13 & 12.8 & 13.5 & 13 & 12.7 & 25.7 & 12 & 12.3 & 11 & 1.325 \\
\hline Pacing & 5.9 & 6.7 & 33.6 & 33.4 & 33.6 & 35.2 & 33.5 & 34.1 & 65.9 & 34.6 & 36.9 & 27.7 & 3.308 \\
\hline Secretive & 1.2 & 149.2 & 0.5 & 0.5 & 0.5 & 0.4 & 0.6 & 0.4 & 0.8 & 0.5 & 0 & 0.2 & 0.066 \\
\hline $\begin{array}{l}\text { Social } \\
\text { Interaction }\end{array}$ & 0.9 & 2023.3 & 3.5 & 2.2 & 2.1 & 2.1 & 1.9 & 2.4 & 4.7 & 2.8 & 1.8 & 2.1 & 0.289 \\
\hline Walking & 5.6 & 9.9 & 63.1 & 63.2 & 62.8 & 64.3 & 63.1 & 62.2 & 123.1 & 63.2 & 64.6 & 54 & 6.152 \\
\hline
\end{tabular}

Table 5. Pearson's Correlation Matrix for instantaneous behavioural sampling data with focal behavioural samplings, F1, F2, F3, etc at 1,2,3, etc. minutes intervals, showing that 'correlation' reduced with increasing time interval. NS = Not significant at $5 \%$ level.

\begin{tabular}{|l|c|c|c|c|c|c|c|c|c|}
\hline Behaviour & F1 & F2 & F3 & F4 & F5 & F10 & F15 & F20 & F30 \\
\hline Bathing & 0.97 & 0.844 & 0.863 & 0.767 & 0.924 & 0.909 & 0.775 & 0.789 & 0.74 \\
\hline Bipedal Stand & 0.932 & 0.745 & 0.757 & 0.656 & 0.708 & 0.504 & 0.455 & 0.291 & 0.338 \\
\hline Climbing & 1 & 0.997 & 0.992 & 0.983 & 0.99 & 0.968 & 0.963 & 0.876 & 0.902 \\
\hline Coiling & 0.991 & 0.935 & 0.907 & 0.815 & 0.8 & 0.626 & 0.79 & 0.32 & 0.515 \\
\hline Digging & 0.999 & 0.989 & 0.977 & 0.982 & 0.961 & 0.884 & 0.858 & 0.775 & 0.757 \\
\hline Drinking & 0.973 & 0.839 & 0.848 & 0.773 & 0.791 & 0.733 & 0.71 & 0.629 & 0.541 \\
\hline Exploration & 0.967 & 0.912 & 0.835 & 0.872 & 0.751 & 0.718 & 0.618 & 0.61 \\
\hline Feeding & 0.997 & 0.976 & 0.972 & 0.972 & 0.957 & 0.827 & 0.568 & 0.664 & 0.393 \\
\hline Pacing & 1 & 0.996 & 0.995 & 0.995 & 0.993 & 0.981 & 0.964 & 0.977 & 0.915 \\
\hline Secretive & 0.987 & 0.925 & 0.963 & 0.821 & 0.874 & 0.805 & 0.786 & $-0.043^{\text {NS }}$ & $0.123^{\text {NS }}$ \\
\hline Social Interaction & 0.91 & 0.823 & 0.855 & 0.698 & 0.713 & 0.655 & 0.637 & 0.442 & 0.305 \\
\hline Walking & 0.999 & 0.989 & 0.988 & 0.989 & 0.986 & 0.973 & 0.898 & 0.961 & 0.904 \\
\hline
\end{tabular}

utilization' during total activity time, the time spent by pangolins over different substrates namely ground, water, mound, and enrichment material, were estimated and analysed.

\section{RESULTS}

The 12 behaviours compared between six Indian Pangolins (Table 1) were presented in the ethogram (Table 2). Mean time spent ( \pm standard deviation) in different behaviours (in minutes) by individual Indian Pangolins is given in Table 3. This study used analysis of focal behavioural sampling data as the standard to compare instantaneous sampling data at different interval. Means and standard errors for all behaviours 
Table 6. Value for LSD (Fisher's Least Significant Difference) and group mean difference between focal (F0) and instantaneous behavioural sampling (F1, F2 etc.). ' ${ }^{* \prime}=$ Value of 'mean differences' > LSD.

\begin{tabular}{|c|c|c|c|c|c|c|c|c|c|c|}
\hline Behaviour & LSD & F0- F1 & F0- F2 & FO- F3 & FO- F4 & F0- F5 & F0- F10 & F0- F15 & FO- F20 & F0- F30 \\
\hline Bathing & 0.263 & 0.003 & 0.003 & 0.013 & 0.04 & 0.032 & $0.31^{*}$ & 0.166 & 0.122 & 0.166 \\
\hline Bipedal Stand & 0.387 & 0.113 & 0.115 & 0 & 0.276 & 0.142 & $0.667^{*}$ & 0.311 & 0.111 & $0.527^{*}$ \\
\hline Climbing & 0.775 & 0.015 & 0.022 & 0.013 & 0.067 & 0.001 & 0.544 & 0.042 & 0.032 & 0.05 \\
\hline Coiling & 0.459 & 0.023 & 0.002 & 0.163 & 0.035 & 0.134 & $0.689 *$ & 0.298 & 0.031 & 0.093 \\
\hline Digging & 1.736 & 0.021 & 0.062 & 0.027 & 0.111 & 0.023 & $5.07^{*}$ & 0.101 & 0.434 & 1.247 \\
\hline Drinking & 0.497 & 0.014 & 0.053 & 0.109 & 0.173 & 0.181 & $1.066^{*}$ & 0.263 & 0.099 & 0.757 \\
\hline Feeding & 1.941 & 0.076 & 0.284 & 0.383 & 0.103 & 0.383 & $12.58^{*}$ & 1.072 & 0.774 & $2.08^{*}$ \\
\hline Exploration & 1.225 & 0.251 & 0.296 & 0.979 & 0.276 & 0.045 & $6.457^{*}$ & 0.716 & 0.097 & 0.066 \\
\hline Pacing & 6.562 & 0.137 & 0.005 & 1.6 & 0.044 & 0.559 & $32.29 *$ & 1.001 & 3.336 & 5.83 \\
\hline Secretive & 0.27 & 0.051 & 0.045 & 0.06 & 0.099 & 0.029 & $0.34^{*}$ & 0.064 & $0.42^{*}$ & $0.276^{*}$ \\
\hline Social Interaction & 0.365 & $0.698^{*}$ & $0.743^{*}$ & $0.737^{*}$ & $0.834 *$ & $0.603 *$ & $0.556^{*}$ & $0.384 *$ & $0.873^{*}$ & $0.744^{*}$ \\
\hline Walking & 10.399 & 0.083 & 0.308 & 1.17 & 0.069 & 0.927 & $59.93^{*}$ & 0.009 & 1.419 & 9.106 \\
\hline
\end{tabular}

comparing different sampling techniques are given in Table 4. Correlation values were determined between focal sampling and instantaneous sampling. Behaviours measured at 1-minute intervals were highly significant with focal samples $(r>0.92, P<0.05)$. Focal behavioural samples significantly correlated $(P<0.05)$ with instantaneous samples up to 15 minute intervals. The correlation values gradually decreased with the increase in sampling intervals (Table 5). Taking individual behaviours into consideration, walking ( $r=0.904$, $P<0.05)$, pacing $(r=0.915, P<0.05)$ and climbing $(r=0.876$, $\mathrm{P}<0.05$ ) behaviours are highly correlated in all the intervals of instantaneous sampling. We also found that the repeatability of the behaviours have a significant negative correlation with the mean time spent in that behaviour $\left(r_{s}=-0.721 ; P=0.008\right)$. By comparing the difference of means between focal samples and instantaneous samples with LSD value, it was found that the mean values of the behaviours, except social interaction samples, with interval $\leq 5$ minutes were not significantly different from focal samples (Table 6).

A peak in activity was observed between 2000-2100 $\mathrm{hr}$ in the present study on Indian Pangolins, except for the pangolin P395, which was found most active between $2300-2400 \mathrm{hr}$, followed by decreasing activity thereafter (Fig. 1). Pangolins were active, i.e., exhibited different behaviour over ground for 129.02 \pm 46.45 minutes ( $\mathrm{N}=81$ days) on average in a day during the study period. Out of the total active period, time spent on different behaviour were feeding $(14 \pm 4.32 \%, N=6)$, drinking $(0.72 \pm 0.56 \%, N=6)$, bipedal stand $(2.3 \pm 1.73 \%$,
$\mathrm{N}=6)$, coiling $(0.61 \pm 0.43 \%, \mathrm{~N}=6)$, digging $(3.67 \pm 3.65 \%$, $\mathrm{N}=6)$, exploration $(6.59 \pm 3.91 \%, \quad \mathrm{~N}=6)$, climbing $(0.68 \pm 0.64 \%, N=6)$, bathing $(0.18 \pm 0.06 \%, N=6)$, walking (59.34 $\pm 22.33 \%, N=6)$, and secretive $(1.84 \pm 0.83 \%, N=6)$. For two pangolins social interaction scored $1.35 \pm 0.63 \%$, and pacing was $19.18 \pm 15.15 \%$. The beginning of activity was usually directed towards feeding behaviour that started $3.5 \pm 1.8$ minutes ( $\mathrm{N}=81$ days) after emergence of pangolins from burrows, except the pangolin P395 (30.8 \pm 24.6 minutes). Mean time allocated in individual pangolins is given in Fig. 2. The differences in equitability of behavioural diversity exhibited were tested for individual pangolins. No significant difference was observed in behavioural diversity $(F=0.577, N=6$, $P=0.719) ;$ with Shannon-Weiner diversity index $(H)$ value, $0.791>\mathrm{H}>1.586$. It was found that pangolins spent most of the time on the ground $(73.25 \pm 58.23 \%)$ exhibiting, walking, pacing, digging and coiling behaviour (Fig. 3). The time spent near the feeding platform is the second highest $(9.66 \pm 4.28 \%)$ that spend for feeding and associated behaviours. Pangolins used the enrichment items $(2.99 \pm 2.35 \%)$ for climbing behaviour. They used given water pools $(0.82 \pm 0.78 \%)$ for drinking, bathing, water inspecting behaviour. Time spent in mound utilisation $(2.76 \pm 2.41 \%)$ includes walking over mound and mound inspecting behaviours. 

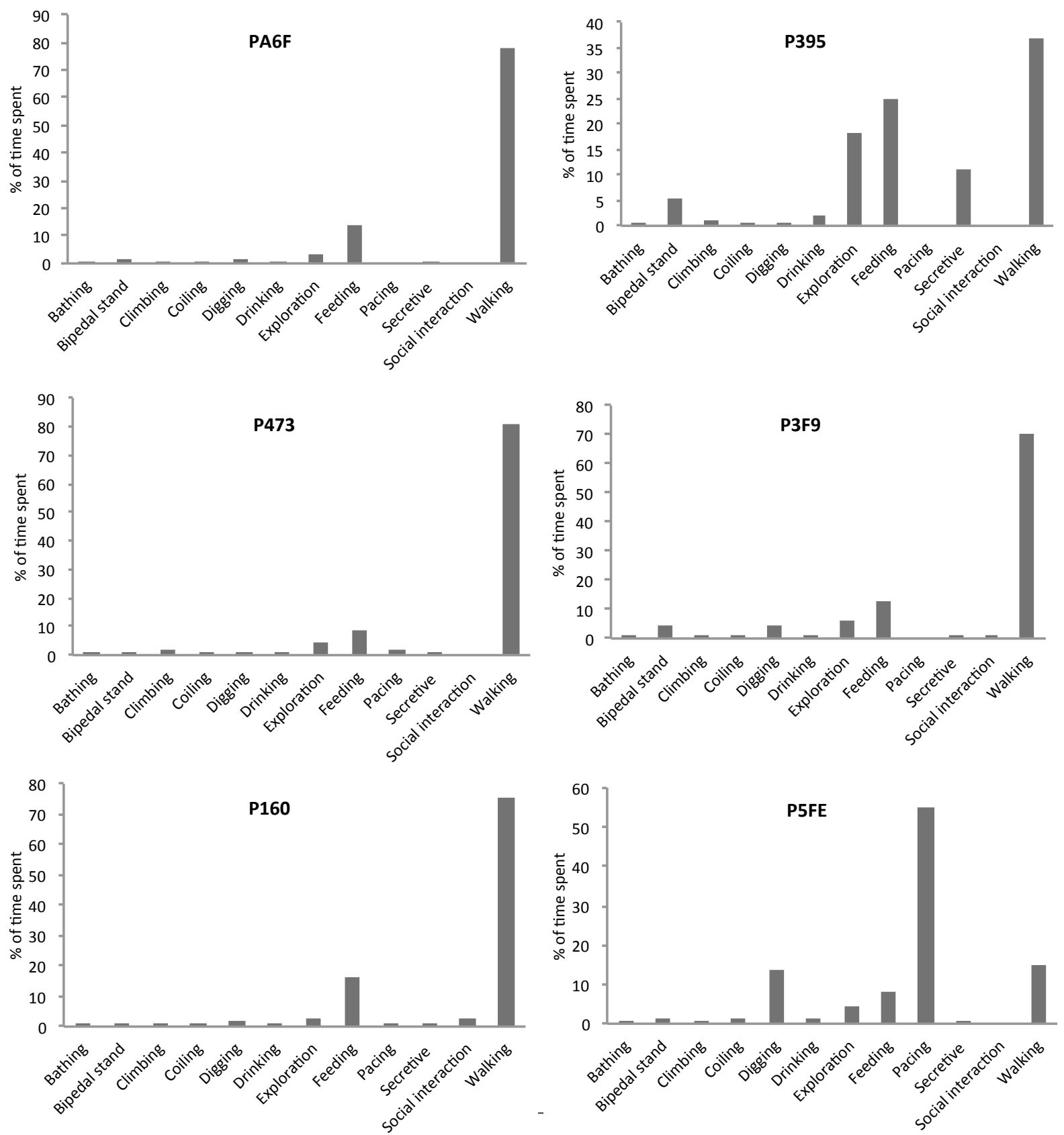

Figure 2. Mean time allocation in different behaviours in individual Indian Pangolins at captivity. Data presented here refer to Table 3. Behaviour types refer to description in Table 2.

\section{DISCUSSION}

\section{Behavioural sampling}

An observational study should show that their sampling technique is reliable, i.e., they have small errors of measurement and that the scores of individuals show stability, consistency, and dependability for behaviour being studied. If the measure is not reliable, it cannot be expected to show lawful relationships with other variables being studied (Mitchell 1979). In most behavioural studies the standard is focal sampling (Mitlohner et al. 2001) but instantaneous sampling is not uncommon. Instantaneous sampling proved to be an accurate reflection of the amount of time spent by an animal in various behaviours (Leger 1977). Several studies have used instantaneous sampling technique with one minute (Bashaw et al. 2003, 2007; Skibiel et al. 2007; Macri \& Patterson-Kane 2011), two minutes 


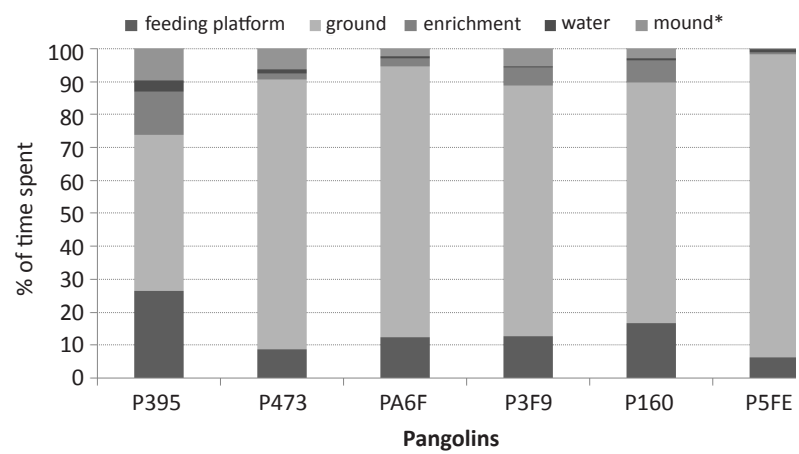

Figure 3. Mean time allocation in enclosure space utilisation by Indian Pangolins. Key: * Over mound activity refer to behaviour like walking over mound.

(Anderson et al. 2010), 15 minutes (Lyons et al. 1997) and 9-19 minutes (Vickery \& Mason 2004) intervals to study behaviour and their temporal changes in different animals in captivity. Challender et al. (2011) used scan (instantaneous) sampling with 15 minutes to study feeding, locomotion, social behaviour and the activity pattern of Sunda Pangolins Manis javanica. Mishra \& Panda (2010) used instantaneous sampling with 10 minutes interval to study the walking, digging, feeding, drinking, climbing behaviour of Indian Pangolins. The results of the present study indicate that instantaneous sampling techniques with relatively short interval lengths $(1,2,3,4,5$ minutes) can be used reliably for measuring behaviours and significantly support focal samples, except social interaction behaviour (Table 5). This may be due to less repeatability of the behaviour (Table 3) than other behaviours. Therefore the study suggests use of focal sampling to record social interaction behaviour. Besides, repeatability of behavioural measures also depends on the bout duration of the behaviour. Studies have shown that the shorter the interval the more accurate duration is obtained from time sampling (Powell et al. 1975; Sanson-Fisher et al. 1980). If short-duration behaviours are of interest and percentage observation time is the response dimension of interest it is wise to choose shorter intervals as far as possible.

Instantaneous sampling is often useful to avoid arbitrary definitions of behaviour's start and end time, which may be difficult to specify. It needs less time and number of efforts than focal sampling, and it can easily be carried out in conjunction with sampling other behavioural and ecological data (Doran 1992). One can study the behaviour of animals by circular scan in particular interval of time and that interval can be used for recording data from another animal. Instantaneous sampling can improve efficiency by avoiding observer fatigue and inability to process desired volume of information. If the initial observation yield a high correlation between focal behavioural sampling and instantaneous sampling, the investigator may use the later for further recording to save time and efforts. These outcomes lead many to recommend instantaneous sampling as a mode of choice (Dunbar 1976; Leger 1977; Powell et al. 1977; Shahon-Fisher et al. 1980; Ary \& Suen 1983; Tagha et al. 1985).

\section{Activity pattern}

The result obtained in this study is similar to that of Mishra \& Panda (2010) that report captive Indian Pangolins spend most of their time walking inside the enclosure under simulated conditions of surroundings. The time of sunset plays a role in initiating the activities of the pangolins and the activity pattern recorded for each individual is very specific to each (Mishra \& Panda 2010). Results from the present study suggest that the pangolins were active intermittently between 1700 and $0500 \mathrm{hr}$. This is similar to the activity pattern reported for Sunda Pangolins by Challender et al. (2011). The peak period of activity was during 2000-2100 hr with one individual variation. Pangolin P395 was most active during 2300-2400 hr. It is clear from the present study that variations in behavioural diversity were observed between individual pangolins. Stereotypic pacing behaviour was observed in some of the individuals, predominantly in P5FE $(55.04 \pm 30.91 \%, \mathrm{~N}=81$ days) and $\mathrm{P} 473(2.29 \pm 2.13 \%, \mathrm{~N}=81$ days). The forms and frequencies of pacing observed in this study were comparable to those reported from Sunda Pangolins (Challender et al. 2011). Maintaining Indian Pangolins in natural enclosures, in which they can perform a full range of natural behaviour and exert control over their environment, is likely to offer some protection against behavioural deficits. Furthermore, environmental enrichment has had some success in reducing the development of stereotypes (Bashaw et al. 2003, 2007; Skibiel et al. 2007). Development of environmental enrichment for Indian Pangolin is a matter for further study.

\section{REFERENCES}

Ary, D. \& H.K. Suen (1983). The use of momentary sampling to assess both frequency and duration of behaviour. Journal of Behavioral Assessment 5(2): 143-150; http://dx.doi.org/10.1007/BF01321446

Altmann, J. (1974). Observational study of behavior: Sampling methods. Behaviour 49: 227-267.

Anderson, C., A.S. Arun \& P. Jensen (2010). Habituation to environmental enrichment in captive sloth bears-effect on stereotypies. Zoo Biology 29(6): 705-714; http://dx.doi. 
org/10.1002/zoo.20301

Bashaw, M.J., M.A. Bloomsmith, M.J. Marr \& T.L. Maple (2003). To Hunt or Not to Hunt? A feeding enrichment experiment with captive large Felids. Zoo Biology 22: 189-198; http://dx.doi.org/10.1002/ zoo.10065

Bashaw, M.J., A.S. Kelling, M.A. Bloomsmith \& T.L. Maple (2007) Environmental Effects on the Behavior of Zoo-housed Lions and Tigers, with a Case Study of the Effects of a Visual Barrier on Pacing. Journal of Applied Animal Welfare Science 10(2): 95-109; http:// dx.doi.org/10.1080/10888700701313116

Chainy, G.B.N., G. Mishra \& P.K. Mohanty (2004). Biostatistics: Theory and Applications. Kalyani Publishers, New Delhi, 353 pp.

Challender, D.W.S., N.V. Thai, M. Jones \& L. May (2011). Time-Budgets and Activity Patterns of Captive Sunda Pangolins (Manis javanica). Zoo Biology 29: 1-13; http://dx.doi.org/10.1002/zoo.20381

Doran, D.M. (1992). Comparison of instantaneous and locomotor bout sampling methods: A case study of adult male chimpanzee locomotor behavior and substrate use. American Journal of Physical Anthropology 89: 85-99; http://dx.doi.org/10.1002/ ajpa.1330890108

Dunbar, R.I.M. (1976). Some aspects of research design and there implication in observational study of behaviour. Behaviour 58: 7898.

Eisenberg, J.F. (1981). The Mammalian Radiations: An Analysis of Trends in Evolution, Adaptation and Behaviour. University of Chicago Press, Chicago.

Engel, J. (1996). Choosing an appropriate sample interval for instantaneous sampling. Behavioral Processes 38: 11-17; http:// dx.doi.org/10.1016/0376-6357(96)00005-8

Fragaszy, D.M., S. Boinsk \& J. Whipple (1992). Behavioral sampling in the field: comparison of individual and group sampling methods. American Journal of Primatology 26: 259-275; http://dx.doi. org/10.1002/ajp.1350260404

Heath, M.E. (1995). Manis crassicaudata. Mammalian Species 531 1-4.

Kleiman, D.G. (1992). Behavior research in zoos: past, present, and future. Zoo Biology 11: 301-312; http://dx.doi.org/10.1002/ zoo.1430110502

Leger, D.W. (1977). An empirical evaluation of instantaneous and onezero sampling of chimpanzee behaviour. Primates 18(2): 367-369; http://dx.doi.org/10.1007/BF02383116

Lehner, P.N. (1996). Handbook of Ethological Methods. $2^{\text {nd }}$ Edition. Cambridge University Press, Cambridge, UK, 403pp.

Losito, M.P., R.E. Mirarchi \& G.A. Baldassarre (1989). New techniques for time-activity studies of avian flocks in view restricted habitats Journal of Field Ornithology 60(3): 388-396.

Lyons, J., R.J. Young \& J.M. Deag (1997). The effects of physical characteristics of the environment and feeding regime on the behavior of captive felids, Zoo Biology 16: 71-83; http://dx.doi. org/10.1002/(SICI)1098-2361(1997)16:1<71::AID-ZOO8>3.0.CO;2-8

Macri, A.M. \& E. Patterson-Kane (2011). Behavioural analysis of solitary versus socially housed Snow Leopards (Panthera uncia), with the provision of simulated social contact. Applied Animal Behaviour Science 130: 115-123; http://dx.doi.org/10.1016/j. applanim.2010.12.005

Magurran, A.E. (1988). Ecological Diversity and Its Measurements. Princeton University Press, New Jersey, 192pp.

Martin, P. \& P. Bateson (1993). Measuring Behaviour: An Introductory Guide. Cambridge University Press, London, UK, 222pp.

Meier, U. (2006). A note on the power of Fisher's least significant difference procedure. Pharmaceutical Statistics 5: 253-263; http:// dx.doi.org/10.1002/pst. 210

Mishra, S. \& S. Panda (2010). Nocturnal behaviour of Indian Pangolin (Manis crassicaudata) in captivity. Indian Zoo Year Book VI: 128-136.

Mitchell, S.K. (1979). Interobserver Agreement, Reliability, and Generalizability of Data Collected in Observational Studies. Psychological Bulletin 86(2): 376-390; http://dx.doi. org/10.1037/0033-2909.86.2.376

Mitlöhner, F.M., J.L. Morrow-Tesch, S.C. Wilson, J.W. Dailey \& J.J. McGlone (2001). Behavioral sampling techniques for feedlot cattle. Journal of Animal Science 79: 1189-1193.

Molur, S. (2008). Manis crassicaudata. In: IUCN 2013. IUCN Red List of Threatened Species. Version 2013.1. <www.iucnredlist.org>. Downloaded on 02 November 2013.

Powell, J., A. Martindale \& S. Kulpan (1975). An evaluation of timesample measures of behavior. Journal of Applied Behavior Analysis 8(4): 463-469; http://dx.doi.org/10.1901/jaba.1975.8-463

Powell, J., B. Martindale, S. Kulp, A. Martindale \& R. Bauman, (1977). Taking a closer look: time sampling and measurement error. Journal of Applied Behavior Analysis 10: 325-332; http://dx.doi. org/10.1901/jaba.1977.10-325

Sanson-Fisher, R., A. Poole \& J. Dunn (1980). An empirical method for determining an appropriate length for recording behaviour. Journal of Applied Behavior Analysis 13: 493-500; http://dx.doi. org/10.1901/jaba.1980.13-493

Skibiel, A.L., H.S. Trevino \& K. Naugher (2007). Comparison of Several Types of Enrichment for Captive Felids. Zoo Biology 26: 371-381; http://dx.doi.org/10.1002/zoo.20147

Tagha, T.C., P.A. Vohs \& G.C. Iverson (1985). A comparison of interval and continuous sampling methods for behavioural observations. Journal of Field Ornithology 56(3): 258-264.

Tinbergen, N. (1951). The Study of Instinct. Oxford University Press, New York, xii+237pp.

Tyler, S. (1979). Time sampling: a matter of convection. Animal Behavior 27: 801-810.

Vickery, S. \& G. Mason (2004). Stereotypic behavior in Asiatic black and Malayan sun bears. Zoo Biology 23: 409-430; http://dx.doi. org/10.1002/zoo.20027

Watters, J.V., S.W. Margulis \& S. Atsalis (2009). Behavioral Monitoring in Zoos and Aquariums: A Tool for Guiding Husbandry and Directing Research. Zoo Biology 28: 35-48; http://dx.doi.org/10.1002/ zoo. 20207

Zar, J.H. (1984). Biostatistical Analysis. $5^{\text {th }}$ Edition. Prentice Hall, New Jersey, xiii+944pp. 